\title{
A study of transformational leadership, strategic flexibility, and firm performance: The moderating role of environmental dynamism
}

\author{
Weining Li \\ South China University of Technology \\ Jingyu Zhan \\ South China University of Technology \\ Yuan Lu \\ Shantou University
}

\section{Recommended Citation}

Li, W., Zhan, J., \& Lu, Y. (2016). A study of transformational leadership, strategic flexibility, and firm performance: The moderating role of environmental dynamism. International Interdisciplinary BusinessEconomics Advancement Journal, 1(2), 73-84. 


\title{
A Study of Transformational Leadership, Strategic Flexibility, and Firm Performance: The Moderating Role of Environmental Dynamism
}

\author{
Weining $\mathrm{Li}^{1}$, Jingyu Zhan ${ }^{2}$, and Yuan $\mathrm{Lu}^{3}$ \\ School of Business Management \\ South China University of Technology, China \\ 1adweinli@scut.edu.cn \\ 21185690289@qq.com \\ Business School \\ Shantou University, China \\ ${ }^{3}$ ylv@stu.edu.cn
}

\begin{abstract}
The relationship between leadership behavior and firm performance has always been a focus of academic research. This study offers a theoretical model that examines strategic flexibility as an intermediate mechanism in the relationship between transformational leadership and firm performance. On the basis of the dynamic environment in China, we tested environmental dynamism as a moderator in this relationship, empirically validated our hypotheses. We conducted questionnaire surveys of the senior managers of 328 companies located mainly in Beijing, Shanghai, and Guangdong, and received 210 valid samples. The results show that strategic flexibility has a fully mediating role in the relationship between transformational leadership and firm performance. Moreover, environmental dynamism was found to moderate the relationship between transformational leadership and strategic flexibility, as well as having moderating effects on the relationship between strategic flexibility and firm performance. These conclusions indicate that strategic flexibility and environmental dynamism influence the effect of transformational leadership on firm performance.
\end{abstract}

Keywords: transformational leadership, strategic flexibility, environmental dynamism, firm performance

\section{Introduction}

Strategic flexibility is a type of dynamic capability and is a fundamental method in the sustainable development of enterprises ( $\mathrm{Li} \&$ Tang, 2010). Strategic flexibility describes the capability of enterprises to respond to environmental change promptly and effectively (Sanchez, 1997). When an enterprise is affected by perceived environmental change and is developing strategic flexibility, a strategic leader is essential. A CEO holds the core position of strategic leadership, controlling and commanding the relevant resources to achieve an enterprise's objectives and playing a crucial role in the process of strategic development and implementation (Dutton \& Duncan, 1987). Whether a CEO can influence, inspire, and stimulate the initiative and dedication of the members 
of a top management team (TMT), create a good organizational learning atmosphere, inspire team members' innovation, and achieve the improvement of firm performance, depends on whether the CEO can lead the enterprise to change (Chen, Wang, \& Yang, 2012). This type of leadership is called transformational leadership by Burns (1978). Transformational leadership can not only change and adjust individual employees' consciousness, but can also encourage a change in the TMTs' consciousness, mining their potential and enabling them to lead enterprises to actively respond to complex and changing environments. Transformational leadership thereby enhances strategic flexibility, builds core competitiveness, and realizes effective business performance. However, the existing literature indicates that research on transformational leadership has mainly concentrated on the effect of transformational leadership behavior on individuals (Chen, 2010). Few studies have focused on how transformational leadership behavior affects the enterprise or organizational level, promoting the establishment of a competitive advantage and improving firm performance. Although some scholars have studied the intermediate variables of corporate culture-such as the mediating roles of entrepreneurial spirit, competitive strategy, organizational learning, and innovation between transformational leadership behavior and firm performanceresearch on the mechanism of this effect has been limited (Bass, 1985). Studies that have addressed the psychological characteristics of transformational leadership behavior regarding the effects and mechanisms at the enterprise level are typically more focused, and neglect the influence of corporate leaders on the dynamic capabilities of the enterprise (Colbert, Kristofbrown, Bradley, \& Barrick, 2008). Fortunately, research has begun to focus on how transformational leadership can enhance an enterprise's strategic flexibility (Wang \& Zhao, 2014), as well as the role of organizational ability in the black box mechanism of firm performance (García-Morales, LlorénsMontes, \& Verdú-Jover, 2008). These studies have implications for the introduction of flexible strategies for studying the effect of transformational leadership on firm performance.

Contemporary Chinese enterprises are facing a complicated and changing environment. How to obtain a lasting competitive advantage is the focus of research in the field of strategic management (Lin, Zhao, \& Li, 2014). Compared with developed Western countries, China is in a critical period of economic restructuring. With the development of economic globalization, technological innovation and market competition have become increasingly fierce (Luo, Men, \& Zhong, 2014). The dynamic environment has become the key environmental characteristic that Chinese enterprises should consider when developing strategies. On the basis of upper echelons theory, this research analyzes the relationship between transformational leadership, strategic flexibility, and firm performance models in the context of dynamic environments. The aim is to understand the effect of transformational leadership on the black box mechanism of firm performance from the angle of strategic flexibility.

\section{Literature Review}

\section{Transformational Leadership and Firm Performance}

Transformational leadership was first described in Rebel Leadership: Commitment and Charisma in the Revolutionary Process by Downton (1973). Subsequently, on the basis of the research of Burns (1978), the concept of transformational leadership was further defined by Bass (1985), who stated that transformational leadership allows subordinates to assume tasks of meaning and value, stimulating their high-level requirements and encouraging them to transcend their personal interests and be concerned about firm performance. 
Transformational leadership is effective for the establishment of a common vision because it entails focusing on the guidance and motivation of employees, which is conducive to the promotion of staff initiative and further enhances corporate performance. Transformational leaders attach great importance to the concept of emotion and value, paying attention to strengthening communication between employees and promoting employee diversity in the process of leadership. Thus, determining the consistency of an enterprise is facilitated, and its effectiveness can be enhanced (Howell \& Avolio, 1993). The various dimensions of transformational leadership behavior affect firm performance positively. Agle, Nagarajan, Sonnenfeld, \& Srinivasan (2006) showed that transformational leadership can overcome organizational inertia and enable an organization to adapt to its environment more effectively, thereby improving its performance. This leads us to propose the following hypothesis:

- H1: Transformational leadership is positively related to firm performance.

\section{Transformational Leadership and Strategic Flexibility}

Strategic flexibility is a type of adjustment ability that addresses unpredictable environmental changes and has a crucial impact on firm performance (Aaker \& Mascarenhas, 1980). The dynamic ability school (Teece, Pisano, \& Shuen, 2009) divides strategic flexibility into either resource flexibility or capability flexibility. Resource flexibility is the ability to make a company develop, manufacture, distribute, and sell products effectively. Capacity flexibility is the ability to discover new resources and integrate those resources into the dynamic environment, and can be used for innovation and increasing income. Capacity flexibility includes numerous internal factors of the coordination flexibility proposed by Sanchez (1995), and can more effectively determine the strategic flexibility of an enterprise (Wang, Chen, \& Jia, 2011). On the basis of the research of the dynamic capability school, this study defines strategic flexibility as the dynamic ability of an enterprise to obtain a competitive edge in a dynamic environment through the rapid adjustment of strategy and resource allocation.

Upper echelons theory holds that CEOs are the key to developing the strategic flexibility of an enterprise, and that this is achieved through three steps, namely defining the enterprise's vision, selecting its guiding concepts, and explaining its strategy (Shimizu \& Hitt, 2004). CEOs are in the key position in the process of strategic decision-making and their behavior directly affects organizational structure and culture (Elenkov \& Manev, 2005). Organizational structure and culture directly affect enterprise flexibility, which in turn affect enterprise innovation and strategic development. With their spirit of exploration and innovation, transformational leaders disrupt the established learning atmosphere, emphasizing variety and experimentation, and stimulating employees to challenge the status quo, thereby effectively discovering and creating new knowledge and promoting organizational learning (Peng \& Zang, 2012). Organizational learning is held by scholars to be a method for improving the adaptability and efficiency of an organization (Jian, 2000), as well as enhancing the process of strategic flexibility (Senge, 1993). Effective learning ability can promote strategic flexibility to achieve the purpose of effective allocation, as well as the discovery and development of resources. Dynamic environments in turn present higher requirements for strategic flexibility, causing the learning ability of the enterprise to more easily form a high level of strategic flexibility. This leads us to propose the following hypothesis:

- H2: Transformational leadership is positively related to strategic flexibility. 


\section{The Mediating Role of Strategic Flexibility}

\section{Strategic Flexibility and Firm Performance}

Strategic flexibility is an essential source for gaining competitive advantage that involves responding to environmental changes and overcoming organizational inertia (Madba, 1996). Through the flexible use of resources and the process of reconfiguration, strategic flexibility can adapt to changes in the environment, quickly grasping external opportunities and substantially reducing business risks and inertia, which increases the probability of business success (Barreto, 2010). Empirical studies of both Chinese (Yang, Deng, \& Fang, 2010) and non-Chinese enterprises (Nadkarni \& Herrmann, 2010), have shown that strategic flexibility can have a significant positive effect on firm performance. This leads us to propose the following hypothesis:

- H3: Strategic flexibility is positively related to firm performance.

\section{Mediating Role of Strategic Flexibility}

The dynamic capability school emphasizes the cultivation of dynamic ability and the importance of ability in gaining new competitive advantages in changing environments (Teece et al., 2009). Dynamic capability is internalized in the enterprise, which entails the ability to exist in the form of an intermediary. On the basis of resource acquisition, dynamic capability can improve the competitive advantage of enterprises by improving the utilization ratio of resources (Amit \& Schoemaker, 1993). Existing research shows that although resources do not directly affect the competitive advantage of enterprises, they can do so through dynamic capability (Festing \& Eidems, 2011).

Strategic flexibility has the basic characteristics of organization capability; its formation is based on information, and it is the intermediary between enterprise resources and competitive advantage (Amit \& Schoemaker, 1993). By encouraging employees to actively exchange and interact, transformational leadership can establish social networks in the organization, which facilitates the discussion and confirmation of information, thus reducing selective bias errors and improving strategic flexibility (Shimizu \& Hitt, 2004). Therefore, on the basis of dynamic capability theory, this paper argues that transformational leadership exerts an influence on firm performance through the integration of strategic flexibility. This leads us to propose the following hypothesis:

- H4: Strategic flexibility plays an intermediary role in the relationship between transformational leadership and firm performance.

\section{Moderating Role of Environmental Dynamism}

Environmental dynamism refers to the unpredictability and frequency of change of the external environment of an enterprise (Dess \& Beard, 1984). High environmental dynamism is characterized by unpredictable and rapid changes. In a highly dynamic environment, a leader must be sensitive to the environment and possess a spirit of adventure, and the ability to make crucial decisions on the basis of incomplete information (Wallace, Little, Hill, \& Ridge, 2010). Conger and Kanungo (1988) argued that types of effective leadership behavior can weaken the negative influence of the external environment. In dynamic environments, charismatic leadership has enhanced sensitivity to the environment, and can effectively implement reform and innovation, thereby adapting to changes in the external environment (Liu \& Chen, 2009) and increasing the strategic flexibility of the enterprise. This leads us to propose the following hypothesis: 
- H5: When the dynamism of the environment increases, the effect of transformational leadership on strategic flexibility increases.

In a highly dynamic environment, enterprises should rely on the construction of strategic flexibility to obtain competitive advantages (Lin et al., 2014). Increases in environmental dynamism increase the necessity of maintaining a high level of strategic flexibility to effectively respond to changes in the environment and improve performance. In a highly dynamic environment, enterprises must adjust their existing business activities and strategic orientation to address challenges of demand and technological innovation. Strategic flexibility is conducive to improving the internal communication and coordination of an enterprise, as well as enhancing its dynamic competitive advantage, which is positively related to firm performance. In a relatively stable environment, the demand for strategic flexibility is reduced because the pursuit of strategic flexibility leads to increased cost and increased pressure on managers' decisions. Moreover, excessive response reduces the focus on existing strategy. Consequently, the effect of dynamic environments on the relationship between strategic flexibility and firm performance is revealed. This leads us to propose the following hypothesis:

- H6: When the dynamism of the environment increases, the impact of strategic flexibility on firm performance increases.

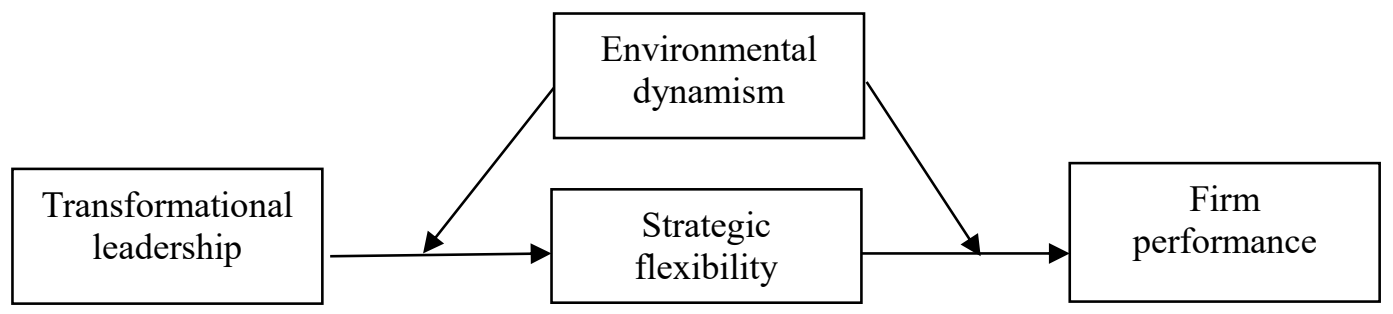

Figure 1: Model of the study

\section{Methodology}

\section{Measures}

Transformational Leadership. This was based on the multi factor leadership behavior questionnaire published by Bass (1999). Transformational leadership behavior is divided into four dimensions, namely leadership, charisma, intellectual stimulation, and personalized care.

Strategic Flexibility. In the relevant literature, strategic flexibility is divided into two dimensions, namely resource capability and resource flexibility. Resource flexibility was measured according to Sanchez (1997) and capability flexibility was measured according to Li, Liu, Duan, and Li (2008).

Environmental Dynamism. This was determined according to Jansen, Van Den Bosch, and Volberda's (2006) measurement.

Firm performance. Return on assets operating was used as a performance indicator in this paper. 
Control variables. We selected the age of the enterprise, the enterprise asset size, the proportion of state-owned shares, and the corporate asset liability ratio as the control variables.

\section{Sample}

The research objects were manufacturing enterprises listed on the Shanghai and Shenzhen stock exchanges, which were selected according to the requirements of the study variables and measurements, data collected through the questionnaire survey, and the combination of secondary data. Data on transformational leadership, strategic flexibility, and dynamic environments were obtained by questionnaire survey. Firm performance and control variables were obtained through the CSMAR database.

Before the investigation, to increase the credibility and feasibility of the questionnaire, the research group first tested 33 enterprises in cities including Guangzhou, Foshan, and Shenzhen. On this basis, the formal questionnaire survey was completed after discussing the subject with relevant experts. The sample enterprises were manufacturing enterprises listed on the Shanghai and Shenzhen stock exchanges before 2010. The survey objects were enterprise managers ranked at the middle level or higher. The survey methods were mail, fax, telephone interviews, and in-person interviews. After more than two months of investigation, a total of 328 questionnaires were issued; the number of valid samples returned was 210 .

\section{Reliability and Discriminant Validity}

The reliability and validity of the measurement instrument were tested before the statistical analysis of the sample, and the consistency, stability, and reliability of the questionnaire were evaluated.

The dimensions of transformational leaderships' Cronbach's $\alpha$ were 0.924, 0.882, 0.860, and 0.889; the total Cronbach's $\alpha$ coefficient was 0.928 . These values show that transformational leadership behavior and its four dimensions had good reliability. We used CFA to test the construct validity of the variables. The four-factor model showed a good fit to the data $\left(\chi^{2} / \mathrm{df}=2.45 ; \mathrm{p}=\right.$ $0.000 ;$ RMSEA $=0.083 ; \mathrm{NFI}=0.884 ; \mathrm{TLI}=0.908 ; \mathrm{CFI}=0.927)$. The transformational leadership behavior had suitable construct validity. The dimensions of the strategic flexibility's Cronbach's $\alpha$ were 0.912 and 0.902 ; the total Cronbach's $\alpha$ coefficient was 0.898 . These results show that strategic flexibility and its four dimensions had appropriate reliability. The four-factor model showed a good fit to the data $\left(\chi^{2} / \mathrm{df}=2.13 ; \mathrm{p}=0.000 ; \mathrm{RMSEA}=0.074 ; \mathrm{NFI}=0.960 ; \mathrm{TLI}=0.968\right.$; $\mathrm{CFI}=0.978$ ). The strategic flexibility had suitable construct validity. The Cronbach's $\alpha$ coefficient for environmental dynamism was 0.826 , which shows that dynamism had favorable reliability.

To examine the distinctiveness of the variables, we compared the measurement model, which consisted of single factors, double factors, and multi factors, for transformational leadership, strategic flexibility, and environmental dynamism. A good fit to the data $\left(\chi^{2} / \mathrm{df}=2.10 ; \mathrm{p}=0.000\right.$; RMSEA $=0.073 ; \mathrm{NFI}=0.918 ; \mathrm{TLI}=0.936 ; \mathrm{CFI}=0.955)$ was the three-factor model. This shows that transformational leadership behavior, strategic flexibility, and environmental dynamism had favorable discriminant validity, and indicates that environmental dynamism simultaneously had appropriate structural validity. 


\section{Data Analysis}

Table 1: Descriptive Statistics and Bivariate Correlations

\begin{tabular}{llllllllll}
\hline Variable & M & SD & $\mathbf{1}$ & $\mathbf{2}$ & $\mathbf{3}$ & $\mathbf{4}$ & $\mathbf{5}$ & $\mathbf{6}$ & $\mathbf{7}$ \\
\hline 1. Age & 16.34 & 5.99 & & & & & & & \\
2. lnAsset & 21.89 & 1.18 & 0.085 & & & & & & \\
3. STShare & 2.05 & 9.61 & $0.189^{* * *}$ & 0.133 & & & & & \\
4. Debt & 41.70 & 20.89 & $0.220^{* *}$ & $0.461^{* *}$ & 0.072 & & & & \\
5. ED & 4.27 & 0.79 & 0.001 & $-0.199^{* *}$ & -0.112 & $-0.200^{* * *}$ & & & \\
6. TL & 4.87 & 0.40 & 0.053 & $-0.318^{* *}$ & -0.080 & $-0.262^{* * *}$ & $0.372^{* *}$ & & \\
7. SF & 4.55 & 0.55 & 0.125 & $-0.249^{* *}$ & -0.027 & $-0.198^{* * *}$ & $0.474^{* *}$ & $0.439^{* * *}$ & \\
8. ROA (\%) & 4.96 & 5.44 & -0.049 & $-0.347^{* * *}$ & 0.049 & $-0.283^{* *}$ & $0.310^{* *}$ & $0.289^{* *}$ & $0.335^{* *}$ \\
\hline
\end{tabular}

Notes: Significant at: $* \mathrm{p}<0.05, * * \mathrm{p}<0.01$, and $* * * \mathrm{p}<0.001 ; \mathrm{ED}=$ Environmental Dynamism;

$\mathrm{TL}=$ Transformational Leadership; SF $=$ Strategic Flexibility

Table 1 shows the mean, standard deviations, and intercorrelations among the variables. The results show that main variables are all positively related: transformational leadership is positively correlated with corporate performance $(\mathrm{r}=0.283, \mathrm{p}<0.01)$; transformational leadership and strategic flexibility are positively correlated $(\mathrm{r}=0.438, \mathrm{p}<0.01)$; strategic flexibility and firm performance are positively correlated $(\mathrm{r}=0.328, \mathrm{p}<0.01)$; and environmental dynamism has a strong correlation with transformational leadership, strategic flexibility, and firm performance.

\section{Findings}

As shown in Table 2, age positively affects strategic flexibility and the scale of the enterprise has a negative impact on strategic flexibility. Transformational leadership is positively related to strategic flexibility $(\mathrm{r}=0.378, \mathrm{p}<0.001)$. $\mathrm{H} 2$ was tested (Model 2). Transformational leadership was positively related to firm performance $(\mathrm{r}=0.190, \mathrm{p}<0.01)$, which confirmed H1. Strategic flexibility was also positively related to firm performance $(r=0.262, \mathrm{p}<0.001)$, which provided support for H3. The method of Baron and Kenny (1986) was proposed for testing the intermediary variables of four regression equations and determined the mediating effect of strategic flexibility. Strategic flexibility was positively related to firm performance, but the impact of transformational leadership behavior was not significant $(r=0.105, \mathrm{p}>0.1)$. This provided support for $\mathrm{H} 4$.

Table 2: Mediating Effect of Strategic Flexibility

\begin{tabular}{lllllll}
\hline Variable & SF & \multicolumn{3}{c}{ FP } & model5 & model6 \\
\hline Age & model1 & model2 & model3 & model4 & model \\
lnAsset & $0.178^{*}$ & $0.132^{*}$ & -0.009 & -0.032 & -0.056 & -0.062 \\
STShare & $-0.193^{*}$ & -0.102 & $-0.287^{* * *}$ & $-0.242^{* *}$ & $-0.237^{* *}$ & $-0.219^{* *}$ \\
Debt & -0.025 & -0.003 & 0.100 & $0.111^{+}$ & $0.107^{+}$ & $0.112^{+}$ \\
TL & $-0.147^{+}$ & -0.081 & $-0.156^{*}$ & $-0.123^{+}$ & -0.117 & -0.105 \\
SF & & $0.378^{* * *}$ & & $0.190^{* *}$ & & 0.105 \\
R & & & & & $0.262^{* * *}$ & $0.224^{* *}$ \\
Adj-R & 0.100 & 0.224 & 0.149 & 0.180 & 0.211 & 0.219 \\
F-value & 0.082 & 0.205 & 0.132 & 0.160 & 0.192 & 0.196 \\
\hline Notes: Signi*** & $5.689^{* * *}$ & $11.781^{* * *}$ & $8.979^{* * *}$ & $8.984^{* * *}$ & $10.917^{* * *}$ & $9.509^{* * *}$ \\
\hline
\end{tabular}

Notes: Significant at: $+\mathrm{p}<0.1,{ }^{*} \mathrm{p}<0.05, * * \mathrm{p}<0.01$, and $* * * \mathrm{p}<0.001 ; \mathrm{TL}=$ Transformational Leadership; SF $=$ Strategic Flexibility; FP = Firm Performance

To assess the moderating role of environmental dynamism on the relationship between transformational leadership and strategic flexibility (H5), we examined three conditions: a. The significant effects of transformational leadership on strategic flexibility $(r=0.378, p<0.001), b$. 
the significant effects of transformational leadership and environmental dynamism on strategic flexibility $(\mathrm{r}=0.264, \mathrm{p}<0.001 ; \mathrm{r}=0.351, \mathrm{p}<0.001)$, and $\mathrm{c}$. the significant interaction $(\mathrm{r}=0.125$, $\mathrm{p}<0.05$ ) between transformational leadership and environmental dynamism in predicting strategic flexibility (after controlling for transformational leadership and environmental dynamism). Thus, H5 was confirmed.

H6 refers to the moderating effect after the mediation effect, known as the moderated mediating effect. According to the test procedures proposed by Zhonglin, Lei and Kit-Tai (2006) to examine the effect, a. transformational leadership positively influences firm performance $(r=0.121, p<$ $0.1)$ and environmental dynamism is also positively related to firm performance $(\mathrm{r}=0.212, \mathrm{p}<$ 0.01; Model 9); b. transformational leadership positively influences strategic flexibility $(\mathrm{r}=0.264$, $\mathrm{p}<0.001)$ and environmental dynamism has a significant impact on strategic flexibility $(\mathrm{r}=0.351$, $\mathrm{p}<0.001$; model 7); c. strategic flexibility is positively related to firm performance $(\mathrm{r}=0.165, \mathrm{p}$ $<0.05)$ and environmental dynamism positively influences firm performance $(\mathrm{r}=0.154, \mathrm{p}<0.05$; Model 10), indicating that the mediation effect of strategic flexibility is significant; and d. the interaction between strategic flexibility and environmental dynamics positively affects $(r=0.137$, $\mathrm{p}<0.05)$ firm performance, which demonstrates that the mediating effect of strategic flexibility on the relation between transformational leadership and performance is moderated by dynamism (model 11). Thus, support for H6 was provided.

Table 3: Moderating Effect of Environmental Dynamism

\begin{tabular}{|c|c|c|c|c|c|c|}
\hline \multirow[b]{2}{*}{ Variable } & \multicolumn{2}{|l|}{ SF } & \multicolumn{4}{|l|}{ FP } \\
\hline & Model 7 & Model 8 & Model 9 & Model 10 & Model 11 & Model 12 \\
\hline Age & $0.124^{*}$ & $0.119^{*}$ & -0.037 & -0.058 & -0.064 & -0.038 \\
\hline $\ln$ Asset & -0.086 & -0.078 & $-0.232^{* *}$ & $-0.218^{* *}$ & $-0.180^{*}$ & $-0.230^{* *}$ \\
\hline STShare & 0.025 & 0.023 & $0.128^{*}$ & $0.124^{+}$ & $0.128^{*}$ & $0.127^{*}$ \\
\hline Debt & -0.048 & -0.059 & -0.103 & -0.095 & $-0.122^{+}$ & -0.105 \\
\hline $\mathrm{TL}$ & $0.264^{* * *}$ & $0.267^{* * *}$ & $0.121^{+}$ & 0.078 & 0.057 & $0.122^{+}$ \\
\hline ED & $0.351^{* * *}$ & $0.351^{* * *}$ & $0.212^{* *}$ & $0.154^{*}$ & $0.147^{*}$ & $0.212^{* *}$ \\
\hline TL*ED & & $0.125^{*}$ & & & & 0.031 \\
\hline SF & & & & $0.165^{*}$ & $0.197^{*}$ & \\
\hline SF*ED & & & & & $0.137^{*}$ & \\
\hline $\mathrm{R}^{2}$ & 0.328 & 0.344 & 0.218 & 0.237 & 0.254 & 0.219 \\
\hline Adj-R ${ }^{2}$ & 0.308 & 0.321 & 0.195 & 0.210 & 0.224 & 0.192 \\
\hline F-value & $16.525^{* * *}$ & $15.104^{* * *}$ & $9.459^{* * *}$ & $8.954^{* * *}$ & $8.536^{* * *}$ & $8.112^{* * *}$ \\
\hline
\end{tabular}

Notes: Significant at: $+\mathrm{p}<0.1,{ }^{*} \mathrm{p}<0.05, * * \mathrm{p}<0.01$, and ${ }^{* * *} \mathrm{p}<0.001 ; \mathrm{TL}=$ Transformational Leadership; ED $=$ Environmental Dynamism; SF = Strategic Flexibility; FP = Firm Performance

On the basis that $\mathrm{H} 4$ and $\mathrm{H} 5$ were established, we further tested whether the moderating effect of environmental dynamism on the relationship between transformational leadership and firm performance is mediated by strategic flexibility. Following Zhonglin et al.'s (2006) test procedures, we regressed firm performance regarding transformational leadership, environmental dynamism, and their interaction. We then examined an insignificant coefficient $(r=0.031, p>0.1)$ associated with the interaction, the results of which indicate that environmental dynamism is not a moderator of the relationship between transformational leadership and firm performance (Table $3)$. 
Therefore, environmental dynamism plays a positive moderating role in the relationship between transformational leadership and strategic flexibility, and also has moderating effects on the relationship between strategic flexibility and firm performance (Figure 2).
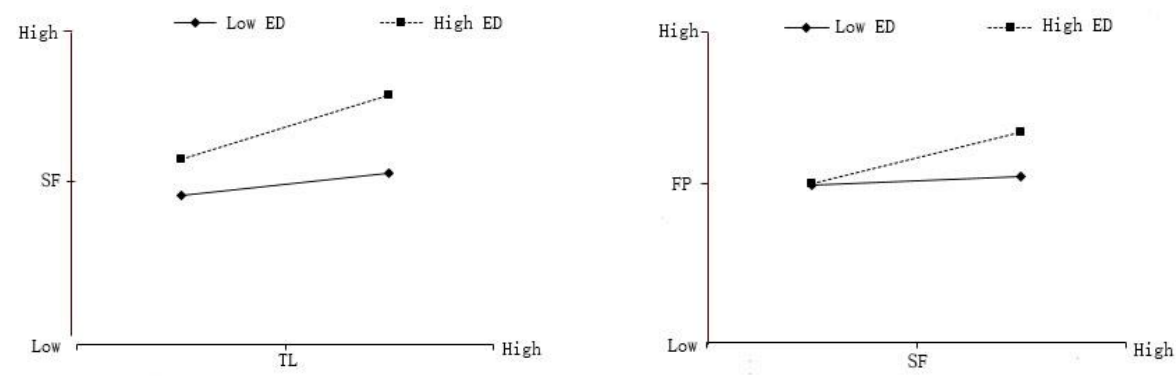

Figure 2: Moderating effect of environmental dynamism

Notes: $\mathrm{TL}=$ Transformational Leadership; $\mathrm{SF}=$ Strategic Flexibility; ED $=$ Environmental Dynamism; FP $=$ Firm Performance

\section{Conclusions}

This study offers a theoretical model that introduces strategic flexibility as an intermediate mechanism in the relationship between transformational leadership and firm performance. We tested environmental dynamism as a moderator in this relationship. The following conclusions can be drawn from the empirical research.

First, strategic flexibility fully mediates the relationship between transformational leadership and firm performance. The results of this study show that strategic flexibility is a capability that exists in the form of an intermediary and can strengthen the competitive advantage of enterprises by facilitating the acquisition of resources and improving their utilization (Amit \& Schoemaker, 1993). Strategic flexibility can convert all types of resources and capabilities acquired by transformational leadership into competitive advantages. The results provide a new perspective for uncovering the black box relationship between transformational leadership behavior and firm performance. The role of strategic flexibility should be addressed during the process of promoting enterprise transformation.

Second, environmental dynamism moderates the relationship between transformational leadership and strategic flexibility. When an organization is operating in a highly dynamic environment, the effect of transformational leadership on strategic flexibility is strengthened. Compared with previous studies (Wang \& Zhao, 2014), this study not only found that transformational leadership behavior has a positive effect on strategic flexibility, but also identified that when an enterprise is operating in a highly dynamic environment, this influence is significantly enhanced.

Third, environmental dynamism plays a positive moderating role between strategic flexibility and firm performance, which is consistent with previous research results (Yang et al., 2010). This confirms that the relationship between strategic flexibility and firm performance is influenced by the dynamic environment. When an enterprise is operating in a highly dynamic environment, this influence is enhanced. 


\section{Theoretical Implications}

This study reveals the crucial influence mechanism of transformational leadership on firm performance, and tested the strategic flexibility and environmental dynamics in which this effect occurs. It thereby provides an essential inspiration for enterprises to obtain competitive advantages in dynamic environments. Research on transformational leadership theory and firm performance has been conducted by Chinese scholars, but seldom from an enterprise level perspective. Moreover, the effect of the dynamic ability of strategic flexibility was unknown. This study is the first to discuss strategic flexibility as an intermediary variable between transformational leadership and firm performance in a Chinese environment on the basis of Western transformational leadership theory. This study further enriches the development of transformational leadership theory, and provides a new perspective to reveal the black box relationship between organizational leaders who exhibit transformational leadership behavior and firm performance.

\section{Practical Implications}

The research results have a definite guiding significance for management practice. First, the role of transformational leadership behavior is affirmed. To improve strategic flexibility and performance, leaders must first develop their ability for transformational leadership. They can then establish an organizational vision and provide intellectual inspiration for subordinates and employees. When the level of strategic flexibility is relatively low, the leader can promote environmental dynamics to produce a sense of crisis in the organization; this can become a positive factor and influence the enterprise to enhance strategic flexibility. Second, companies should increase the emphasis on strategic flexibility. The effect of strategic flexibility on firm performance is also regulated by environmental dynamism. Therefore, in this transitional period in China, companies must adjust and reallocate resources in a timely manner in order to adapt effectively to changes in the social environment and improve firm performance.

\section{Limitations and Future Research}

Some limitations of this study should be considered. First, strategy formation and excellent performance are the result of the long-term interaction between the CEO and the TMT. Further research on the relationship between strategic flexibility and firm performance should be undertaken on the basis of transformational leadership and TMT interaction. Second, homologous errors occurred because the questionnaire was answered by the subjects of the study. Although the existence of homologous error is insufficient to invalidate the conclusions of the study (Doty \& Glick, 1998), selecting different research subjects in future research is necessary. Finally, this study was limited to a specific time period of the cross section of the study. Future research should consider introducing longitudinal design to further verify the mechanism of the effect.

\section{References}

Aaker, D. A., \& Mascarenhas, B. (1984). The need for strategic flexibility. Journal of Business Strategy, 5(2), 7482.

Agle, B. R., Nagarajan, N. J., Sonnenfeld, J. A., \& Srinivasan, D. (2006). Does CEO charisma matter? An empirical analysis of the relationships among organizational performance, environmental uncertainty, and top management team perceptions of CEO charisma. Academy of Management Journal, 49(1), 161-174.

Amit, R., \& Schoemaker, P. J. H. (1993). Strategic assets and organizational rent. Strategic Management Journal, 14(1), 33-46.

Baron, R. M., \& Kenny, D. A. (1986). The moderator-mediator variable distinction in social psychological research: conceptual, strategic, and statistical considerations. Journal of Personality \& Social Psychology, 51(6), 1173-1182. 
Barreto, I. (2010). Dynamic capabilities: A review of past research and an agenda for the future. Journal of Management, 36(1), 256-280.

Bass, B. M. (1985). Leadership performance beyond expectations. Academy of Management Review, 12(4), 5244 5247.

Bass, B. M. (1999). Two decades of research and development in transformational leadership. European Journal of Work and Organizational Psychology, 8(1), 9-32.

Burns, J. M. (1978). Leadership. New York, NY: Harper \& Row.

Chen, J. (2010). An empirical study on the effect of transformational leadership behavior under different dimensions. Economic Science, 25(1), 52-61.

Chen, X., Wang, S., \& Yang, L. (2012). The impact mechanism of transformational leadership on firm performance: Based on a survey of SMEs' leaders. Science of Science \& Management of $S$ \& T, 27(4), 808-810.

Colbert, A. E., Kristofbrown, A. L., Bradley, B. H., \& Barrick, M. R. (2008). CEO transformational leadership: The role of goal importance congruence in top management teams. Academy of Management Journal, 51(1), 81-96.

Conger, J. A., \& Kanungo, R. N. (1988). The empowerment process: Integrating theory and practice. Academy of Management Review, 13(3), 471-482.

Dess, G. G., \& Beard, D. W. (1984). Dimensions of organizational task environment. Administrative Science Quarterly, 29(1), 52-73.

Doty, D. H., \& Glick, W. H. (1998). Common method bias: Does common method variance really bias results? Organizational Research Methods, 1(4), 374-406.

Downton, J. V. (1973). Rebel leadership: Commitment and charisma in the revolutionary process. New York, NY: Free Press.

Dutton, J. E., \& Duncan, R. B. (1987). The influence of the strategic planning process on strategic change. Strategic Management Journal, 8(2), 103-116.

Elenkov, D. S., \& Manev, I. M. (2005). Top management leadership and influence on innovation: The role of sociocultural context. Journal of Management, 31(3), 381-402.

Festing, M., \& Eidems, J. (2011). A process perspective on transnational HRM systems: A dynamic capability-based analysis. Human Resource Management Review, 21(3), 162-173.

García-Morales, V. J., Lloréns-Montes, F. J., \& Verdú-Jover, A. J. (2008). The effects of transformational leadership on organizational performance through knowledge and innovation. British Journal of Management, 19(4), 299-319.

Howell, J. M., \& Avolio, B. J. (1993). Transformational leadership, transactional leadership, locus of control, and support for innovation: Key predictors of consolidated-business-unit performance. Journal of Applied Psychology, 78(6), 891-902.

Jansen, J. J. P., Van Den Bosch, F. A. J., \& Volberda, H. W. (2006). Exploratory innovation, exploitative innovation, and performance: Effects of organizational antecedents and environmental moderators. Erim Report, 52(11), 1661-1674.

Jian, F. (2000). Organizational behavior management. Beijing, China: Renmin University of China.

Li, J., \& Tang, Y. I. (2010). CEO hubris and firm risk taking in china: The moderating role of managerial discretion. Academy of Management Journal, 53(1), 45-68.

Li, Y., Liu, Y., Duan, Y., \& Li, M. (2008). Entrepreneurial orientation, strategic flexibilities and indigenous firm innovation in transitional China. International Journal of Technology Management, 41(1), 223-246.

Lin, Y., Zhao, S., \& Li, N. (2014). A study of network-building HR practices for TMT, strategic flexibility and firm performance: The moderating role of environmental uncertainty. Nankai Business Review International, $5(1), 95-114$.

Liu, Z., \& Chen, J. (2009). Charismatic leadership and self-innovation: Mechanism and contingency. China Industrial Economics, 2009(4), 137-146.

Luo, J., Men, C., \& Zhong, J. (2014). The effect of leadership behavior and team creativity in dynamic environments. Science of Science \& Management of $S$ \& T, 35(5), 172-180.

Madba, V. R. (1996). Strategic flexibility and performance in the global steel industry: The role of interfirm linkages (Doctoral Dissertation, University of Pittsburgh). Retrieved from

https://www.researchgate.net/publication/34038376_Strategic_Flexibility_and_Performance_in_the_Globa 1_Steel_Industry_The_Role_of_Interfirm_Linkages

Nadkarni, S., \& Herrmann, P. (2010). CEO personality, strategic flexibility, and firm performance: The case of the Indian business process outsourcing industry. Academy of Management Journal, 53(5), 1129-1130. 
Peng, C., \& Zang, J. (2012). An empirical analysis on the relationship between team leadership and team learning capability. Science \& Technology Progress \& Policy, 29(15), 142-145.

Sanchez, R. (1995). Strategic flexibility in product competition. Strategic Management Journal, 16(1), 135-159.

Sanchez, R. (1997), Preparing for an uncertain future: Managing organization for strategic flexibility. International Studies of Management \& Organization, 27(2), 71-94.

Senge, P. (1993). The fifth discipline: The art and practice of the learning organization. New York, NY: Doubleday.

Shimizu, K., \& Hitt, M. A. (2004). Strategic flexibility: Organizational preparedness to reverse ineffective strategic decisions. Academy of Management Perspectives, 18(4), 44-59.

Teece, D. J., Pisano, G., \& Shuen, A. (2009). Dynamic capabilities and strategic management. Strategic Management Journal, 18(7), 509-533.

Wallace, J. C., Little, L. M., Hill, A. D., \& Ridge, J. W. (2010). CEO regulatory foci, environmental dynamism, and small firm performance. Journal of Small Business Management, 48(4), 580-604.

Wang, D., \& Zhao, S. (2014). CEO transformational leadership, corporate entrepreneurship and strategic flexibility: An empirical study of SMEs. Science of Science \& Management of $S \& T, 35(6), 12-17$.

Wang, T., Chen, T., \& Jia, R. (2011). An empirical study on the effect of strategic flexibility on enterprise performance. Chinese Journal of Management, 8(3), 388-395.

Yang, Z., Deng, L. J., \& Fang, E. (2010). Market orientation, strategic flexibility and performance: The moderating effect of environmental uncertainty. China Soft Science, 46(9), 130-139.

Zhonglin, W., Lei, C., \& Kit-Tai, H. (2006). Mediated moderator and moderated mediator. Acta Psychologica Sinica, 38(3), 448-452.

\section{Acknowledgements}

We are very grateful for the support from National Natural Science Foundation of China (Grant No.71172073, 71402022), which make this paper more valuable and readable. Any errors that remain are our own. 